\title{
AAN guidelines
}

\author{
A benefit to the neurologist
}

T.S.D. Getchius

\section{L.K. Moses}

J. French, MD, FAAN

G.S. Gronseth, MD,

FAAN

J.D. England, MD,

FAAN

J. Miyasaki, MD, MEd, FAAN

Address correspondence and reprint requests to American Academy of Neurology, 1080 Montreal Avenue, St. Paul, MN 55116

guidelines@aan.com

Neurology $y^{\circledR} 2010 ; 75: 1126-1127$
American Academy of Neurology (AAN) members assign high value to clinical practice guidelines. In a 2006 needs assessment survey, 82\% of members rated guidelines as "important" or "very important." " Moreover, a 2009 survey of a representative sample of AAN members found that $75 \%$ used 1-6 AAN guidelines in the past year. ${ }^{2}$ However, the AAN has received feedback suggesting that guidelines without high-level recommendations (i.e., Level A or B) should not be published because they do not guide practice. Indeed, to account for lower levels of evidence, many specialty medical societies "fill in the gaps" with consensus and expert opinion-based recommendations. The AAN has decided not to incorporate consensus so as not to substitute the judgment of its members with the judgment of an expert panel, and maintains strict adherence to its evidence-based process. This decision was made with full knowledge that it may result in guidelines that are not as prescriptive for practice as many would find desirable. Such policy acknowledges that there are some questions that evidence-based medicine is ill-suited to answer and some important questions for which high-quality research is lacking. Nonetheless, the AAN's guideline development subcommittees (Quality Standards Subcommittee [QSS] and Therapeutics and Technology Assessment Subcommittee [TTA]) believe that AAN guidelines are valuable tools regardless of the level of recommendation they contain. Our reasons for this belief follow.

First, development of these documents involves performing a literature review for all evidence related to an answerable clinical question and grading it according to the AAN's classification scheme. ${ }^{3}$ In view of the volume of literature available, a comprehensive but focused distillation of the evidence itself provides a valuable service to the practicing physician. However, unlike a traditional review article, the AAN's use of a standardized, a priori classification system allows readers to understand the quality of evidence available for a particular clinical question.

Secondly, the members of QSS and TTA believe that reporting the best available current evidence, even if it is low level, is preferable to not reporting anything. Knowing that a particular treatment is probably or possibly effective based on the evidence is better than presuming a treatment is effective or not effective based only on personal experience or opinion. Even those publications ("evidence reports") that provide only Level U recommendations (insufficient data to support or refute use of a particular treatment or diagnostic test) are useful. These reports are valuable, because they identify what we do not know (and oftentimes thought we did). Such information provides impetus for researchers to design studies to address the current gaps in knowledge. Usually, after review of the evidence, the writing group can provide insight on improved study designs that in the future could better address the question.

It is important to note that a Level U guideline recommendation is not synonymous with a negative recommendation. Level U simply states that there is not enough evidence. We cannot say that an intervention or diagnostic modality does work, but we also cannot say that it does not work. This information is provided to give the current state of the evidence when making treatment decisions, which always remain the prerogative of the treating physician. AAN

From the American Academy of Neurology (T.S.D.G., L.K.M.), St. Paul, MN; New York University Comprehensive Epilepsy Center (J.F.), New York; University of Kansas Medical Center (G.S.G.), Kansas City; Louisiana State University Health Sciences Center (J.D.E.), New Orleans; and Toronto Western Hospital (J.M.), Toronto, Canada.

Disclosure: Author disclosures are provided at the end of the article. 
guidelines are written for the primary audience of physicians, and insurers who use Level U recommendations from AAN guidelines to deny treatment coverage misinterpret the evidence. We are not aware of how many insurers use AAN guidelines to deny treatment coverage. We are aware, however, that many insurers take AAN guidelines into account while drafting medical coverage policies. It does not seem unreasonable to conclude that low-level or Level U guidelines may occasionally drive reimbursement denial decisions, just as they may drive positive reimbursement decisions for helpful therapies backed by strong evidence.

Level A recommendations are based on Class I studies, which are the highest quality but least available. If AAN guidelines were required to have Class I evidence or Level A recommendations for publication, there would be few guidelines available. The QSS and TTA select topics based on prevalence of the condition, extent of practice variation, and health and socioeconomic impact, among other factors. Topics are not selected based upon a priori knowledge about whether the evidence will be of high quality. Questions that can be answered by Class I studies are likely to be those that have the least practice variation, due to the strength and consistency of the data. The guideline process is designed to address knowledge gaps. Additionally, if the AAN produced only guidelines on topics with high levels of evidence, we might ignore less common disorders, resulting in changes in distribution of resources, possibly contributing to distributive injustice.

Making rational decisions based upon the best available evidence (also known as evidence-based medicine) is being taught to new medical graduates. Patients now expect health care providers to have an awareness of the evidence (or lack thereof) when making treatment decisions. AAN guidelines aim to meet the needs of the practicing neurologist; therefore, we encourage you to become more involved in the AAN guideline development process by providing feedback and comments on AAN guidelines in process and by volunteering as a member guideline reviewer (http://www.aan.com/go/practice/guidelines/ reviewer), engaging in dialogue with your col- leagues about recent guideline publications in your practice or via AAN Communities (https:// www.aan.com/communities/), and suggesting areas where guidelines should be developed by completing a topic nomination form (http:// www.aan.com/go/practice/guidelines/topic).

\section{DISCLOSURE}

T.S.D. Getchius is a full-time employee of the American Academy of Neurology. L.K. Moses is a full-time employee of the American Academy of Neurology. Dr. French has served on scientific advisory boards for UCB, Johnson \& Johnson, Eisai Inc., Novartis, Valeant Pharmaceuticals International, Icagen, Inc., Ikano Therapeutics Inc., Sepracor Inc., and Marinus Pharmaceuticals, Inc.; has received funding for travel from UCB, Kyowa Hakko Kirin Pharma, Inc., Eisai Inc., Johnson \& Johnson, Valeant Pharmaceuticals International, and GlaxoSmithKline; serves as an Associate Editor of Epilepsy Currents and Supplement Editor for Epileptic Disorders; estimates that $30 \%$ of her time is spent in outpatient epilepsy practice; receives research support from the Epilepsy Therapy Development Project, FACES, Johnson \& Johnson, Eisai Inc., UCB, SK BioPharmaceuticals, Valeant Pharmaceuticals International, Vertex Pharmaceuticals, Pfizer Inc., Merck Serono, the NIH (R01 NS053998$01 \mathrm{~A} 1$ [coinvestigator]), and the Epilepsy Research Foundation; and serves as President of the Epilepsy Study Consortium, which receives money from multiple pharmaceutical companies. A fixed $20 \%$ of her NYU salary is paid by the study consortium, some of which may come from consulting fees from GlaxoSmithKline, Pfizer Inc., UCB, Johnson \& Johnson, Cyberonics, Inc., Schwarz Pharma, Ortho-McNeil-Janssen Pharmaceuticals, Inc., Eisai Inc., Jazz Pharmaceuticals, Ovation Pharmaceuticals, Endo Pharmaceuticals, Bial Pharmaceuticals, NeuroVista Corporation, Valeant Pharmaceuticals International, Icagen, Inc., Supernus Pharmaceuticals, Inc., Ikano Therapeutics Inc., SK Bio-Pharmaceuticals, TaroPharma, NeuroTherapeutics Pharma, Inc., Sepracor Inc., and Novartis. Dr. Gronseth serves as an editorial advisory board member of $\mathrm{Neu}$ rology Now; serves on a speakers' bureau for Boehringer Ingelheim; and receives honoraria from Boehringer Ingelheim and the American Academy of Neurology. Dr. England has served on speakers' bureaus for and received funding for travel and speaker honoraria from Talecris Biotherapeutics and Teva Pharmaceutical Industries Ltd.; serves as an Associate Editor for Current Treatment Options in Neurology; holds stock in Wyeth; has served as an expert witness in a medico-legal case; receives research support from Pfizer Inc., AstraZeneca, and the NIH; and is co-chair of the Quality Standards Subcommittee. Dr. Miyasaki has served on a scientific advisory board for Teva Pharmaceutical Industries Ltd.; has received honoraria for educational activities not funded by industry; serves on the editorial board of Movement Disorders; has received speaker honoraria from Biovail Corporation; serves/has served as a consultant to Janssen-Ortho, Inc., Merz Pharmaceuticals GmbH, Schering-Plough Corp., the NIH (Independent Medical Monitor), Ontario Drug Benefits, and Common Drug Review, Canada; receives research support from Teva Pharmaceutical Industries Ltd., Boehringer Ingelheim, Solvay Pharmaceuticals, Inc., Solstice Neurosciences, Inc., Impax Laboratories, Neurogen, Medivation, Inc., the National Parkinson Foundation, the Parkinson Society Canada, the Michael J. Fox Foundation, and the Huntington Study Group; and is co-chair of the Therapeutics and Technology Assessment Subcommittee.

Received March 26, 2010. Accepted in final form June 7, 2010.

\section{REFERENCES}

1. Needs Assessment Survey. St. Paul: American Academy of Neurology; 2007.

2. Practice Issues Survey. St. Paul: American Academy of Neurology; 2009.

3. Edlund W, Gronseth G, So Y, Franklin G. Clinical Practice Guideline Process Manual. St. Paul: American Academy of Neurology; 2004. 


\section{Neurology}

\section{AAN guidelines: A benefit to the neurologist}

T.S.D. Getchius, L.K. Moses, J. French, et al.

Neurology 2010;75;1126-1127

DOI 10.1212/WNL.0b013e3181f4d883

This information is current as of September 27, 2010

\section{Updated Information \&} Services

Citations

Permissions \& Licensing

Reprints including high resolution figures, can be found at: http://n.neurology.org/content/75/13/1126.full

This article has been cited by 3 HighWire-hosted articles: http://n.neurology.org/content/75/13/1126.full\#\#otherarticles

Information about reproducing this article in parts (figures,tables) or in its entirety can be found online at:

http://www.neurology.org/about/about_the_journal\#permissions

Information about ordering reprints can be found online: http://n.neurology.org/subscribers/advertise

Neurology ${ }^{\circledR}$ is the official journal of the American Academy of Neurology. Published continuously since 1951, it is now a weekly with 48 issues per year. Copyright. All rights reserved. Print ISSN: 0028-3878. Online ISSN: 1526-632X.

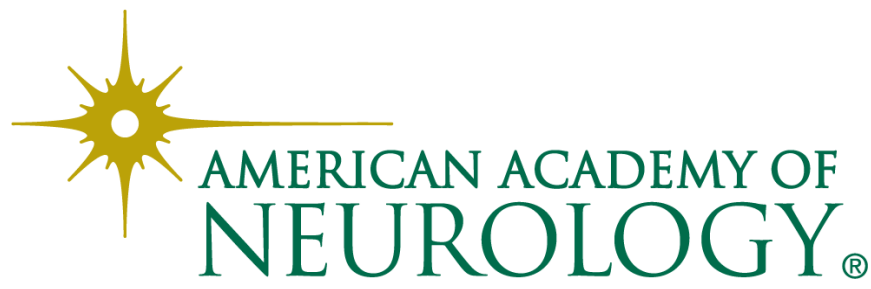

